OPEN ACCESS

Edited by:

Pedro Maireles-Torres,

University of Málaga, Spain

Reviewed by:

Matteo Guidotti,

Italian National Research Council, Italy

Paul-Henri Ducrot,

INRA UMR1318 Institut Jean Pierre

Bourgin, France

Mohammad Boshir Ahmed,

Gwangju Institute of Science and

Technology, South Korea

*Correspondence:

Nadia Lotti

nadia.Iotti@unibo.it

Lisa Moni

lisa.moni@unige.it

${ }^{\dagger}$ These authors have contributed equally to this work

Specialty section:

This article was submitted to Green and Sustainable Chemistry,

a section of the journa

Frontiers in Chemistry

Received: 20 October 2019

Accepted: 27 January 2020

Published: 13 February 2020

Citation:

Lanteri D, Quattrosoldi S, Soccio M, Basso A, Cavallo D, Munari A, Riva $R$

Lotti N and Moni L (2020)

Regioselective Photooxidation of Citronellol: A Way to Monomers for

Functionalized Bio-Polyesters.

Front. Chem. 8:85

doi: 10.3389/fchem.2020.00085

\section{Regioselective Photooxidation of Citronellol: A Way to Monomers for Functionalized Bio-Polyesters}

\author{
Deianira Lanteri ${ }^{1+}$, Silvia Quattrosoldi ${ }^{2+}$, Michelina Soccio ${ }^{2}$, Andrea Basso $^{1}$, \\ Dario Cavallo ${ }^{1}$, Andrea Munari ${ }^{2}$, Renata Riva ${ }^{3}$, Nadia Lotti ${ }^{2 *}$ and Lisa Moni ${ }^{1 *}$
}

${ }^{1}$ Department of Chemistry and Industrial Chemistry, University of Genova, Genova, Italy, ${ }^{2}$ Department of Civil, Chemical, Environmental and Materials Engineering, University of Bologna, Bologna, Italy, ${ }^{3}$ Department of Pharmacy, University of Genova, Genova, Italy

Dye-sensitized photooxygenation reaction of bio-based double bond-containing substrates is proposed as sustainable functionalization of terpenes and terpenoids to transform them into polyoxygenated compounds to be employed for the synthesis of new bio-based polyesters. As proof of concept, citronellol $\mathbf{1}$ has been regioselectively converted into diol 4 using singlet oxygen $\left({ }^{1} \mathrm{O}_{2}\right)$, a traceless reagent that can be generated from air, visible light and zeolite supported-photosensitizer (Thionine-NaY). With our synthetic approach, diol $\mathbf{4}$ has been obtained in two-steps, with good regioselectivity, using green reagents such as light and air, and finally a solvent-free oxidation step. From this compound, a citronellol-based copolyester of poly(butylene succinate) (PBS) has been synthesized and fully characterized. The results obtained evidence that the proposed copolymerization of PBS with the citronellol-based building blocks allows to obtain a more flexible and functionalizable material, by exploiting a largely available natural molecule modified through a green synthetic path.

Keywords: photooxidation, zeolites, terpenoids, poly(butylene succinate), copolymerization, renewable polymers

\section{INTRODUCTION}

Modern society is recording an urgent demand for sustainable, simple and selective synthetic methodologies for the preparation of smart materials and added value compounds (Corma et al., 2007; Kohli et al., 2019).

In the polymer field, the interest for fully bio-based materials has enormously grown up, due to the urgent need to solve the serious environmental pollution problems caused by the extensive use of traditional fossil-based plastics. Poly(butylene succinate) (PBS), synthesized through the well-known two-stage melt polycondensation reaction from 1,4-butanediol and succinic acid, has attracted much attention as promising ecofriendly bioplastic, being characterized by intriguing physical and mechanical properties, similar to those of polyethylene (LDPE), good processability, low cost, and biodegradability. Indeed, PBS has been demonstrated to be suitable for a wide range of different applications, ranging from biomedicine to packaging. It is also interesting to note that bio 1,4-butanediol can be obtained from bio-based succinic acid, this latter derived from biomass or sugar substrates.

In recent years, many works have been published describing the use of PBS in regenerative medicine and for the realization of nanosystems for controlled drug release (Gigli et al., 2016). In this context the biocompatibility of the material is crucial, but also the straightforward 
manipulation to bind biological molecules is of great importance. This property can be achieved through insertion of a comonomer unit in the PBS polymer chain that permits post functionalization. Copolymerization has always been a viable tool (Gigli et al., 2012; Gualandi et al., 2012; Soccio et al., 2012) in this view. It is worth to notice that by means of this strategy, at the same time, it is possible to reduce the stiffness of the final material, through a decrease in the degree of crystallinity.

Within the hydrocarbon-rich biomass, terpenes, and terpenoids represent a vast class of molecules, which are finding wide application in polymer science. These compounds are considered interesting organic feedstock for the generation of green plastics and composites (Wilbon et al., 2013; Winnacker and Rieger, 2015), due to their natural abundance and lowcost. Moreover, new approaches, such as the controlled and sustainable functionalization, have been recently proposed to transform them into monomers for alternative polymerization process, to produce even more competitive polymers (Thomsett et al., 2016). Among all the strategies reported in the literature (Byrne et al., 2004; Zhang et al., 2005; Kobayashi et al., 2009; Lowe, 2010; Firdaus et al., 2011; Firdaus and Meier, 2013; Hauenstein et al., 2016; Roth et al., 2017; Parrino et al., 2018; Stamm et al., 2019; Thomsett et al., 2019), to the best of our knowledge the dye-sensitized photooxygenation of terpenes and terpenoids to obtain bio-based polyhydroxylated monomers and their use for the production of functionalized polyesters, has never been reported. Reactions of singlet oxygen with C-C double bounds are well-known and documented in literature (Schenck et al., 1953; Foote and Wexler, 1964; Alberti and Orfanopoulos, 2010). Since singlet oxygen $\left({ }^{1} \mathrm{O}_{2}\right)$ can be conveniently generated by irradiation of oxygen naturally present in the atmosphere, we envisioned to obtain diols, simply by treatment of terpenes and terpenoids with air, light and a photosensitizer, followed by reduction of the resulting alcohols. Here we present a proof of concept of our idea, describing the photosensitized conversion of ( $\mathrm{rac}$-)citronellol 1 into diol 4, this latter employed to prepare a PBS-based copolymer. The photooxidation of citronellol 1 using ${ }^{1} \mathrm{O}_{2}$ has been well-studied since 90's (Bouamri et al., 1991), as it represents one of the few photochemical processes used at industrial scale, to produce rose oxide, an important fragrance (Monnerie and Ortner, 2001). Typically, the bulk synthesis is conducted in batch, employing Rose Bengal (RB) as sensitizer, an alcoholic solvent, and white lamp or sunlight as light sources. Due to the instability of the hydroxyperoxides 2 and 3, the corresponding alcohols $\mathbf{4}$ and $\mathbf{5}$ are isolated after in situ reduction of the reaction mixture (Scheme 1). Recently, the process has been implemented thanks to the use flow methods (Maurya et al., 2011; Park et al., 2015; Clark et al., 2016; Ioannou et al., 2017; Anselmo et al., 2019), achieving increased efficiency compared to the batch conditions. However, the potential synthetic use of this reaction is suppressed by its poor selectivity, whereas in all cases a mixture of secondary and tertiary alcohols $\mathbf{4}$ and $\mathbf{5}$ is obtained in almost equimolar ratio (Maurya et al., 2011; Park et al., 2015; Clark et al., 2016; Ioannou et al., 2017). Moreover, the ${ }^{1} \mathrm{O}_{2}$ photooxidation of $\mathbf{1}$ suffers safety problems when pure oxygen must be employed, affecting the scalability of the process.

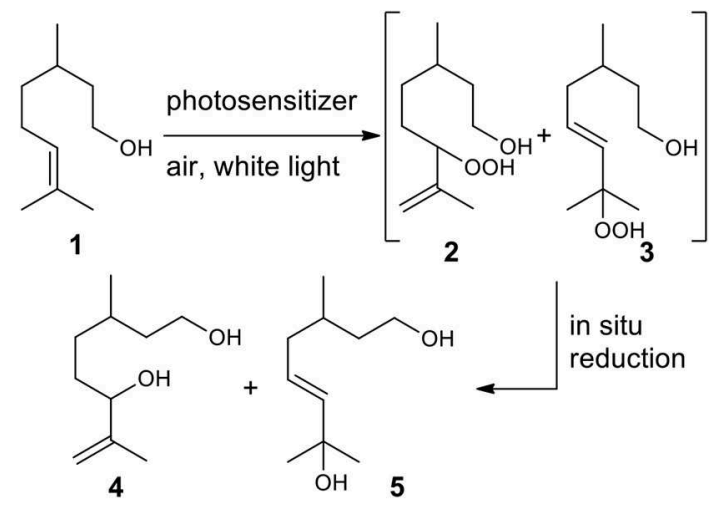

SCHEME 1 | Photooxygenation reaction of (rac-)citronellol $\mathbf{1}$ and subsequent reduction of hydroperxides $\mathbf{2}$ and $\mathbf{3}$ to give diols $\mathbf{4}$ and $\mathbf{5}$.

Regioselectivity in photooxygenation reactions has been successfully achieved for simple trisubstituted alkenes by performing them in a confined space, using molecular containers such as self-assembled molecular hosts (Natarajan et al., 2007; Geer et al., 2013), zeolites (Shailaja et al., 2000; Stratakis and Froudakis, 2000; Kaanumalle et al., 2002; Chen et al., 2005), or microemulsions (Nardello et al., 2004). The confined space allows to better control the conformation of alkene and thus the accessibility of the allylic hydrogen(s) with respect to the attacking singlet oxygen during the hydroperoxide formation. Anyway, in most of these studies, only simple model alkenes have been used in analytical amount, and no scalability of the process has been investigated.

Herein, we describe the photooxidation of $\mathbf{1}$ using air, visible light and zeolite supported-photosensitizer (Thionine$\mathrm{NaY}$ ). With our synthetic approach, diol $\mathbf{4}$ has been obtained in two-steps, with good regioselectivity, using green reagents, such as light and air, and a solvent-free oxidation step. Moreover, the supported catalyst can be recovered by filtration and reused without meaningful loss of activity.

Using diol 4, a random copolyester was synthetized by a solvent free two-stage polycondensation process, starting from a mixture of 4/1,4-butandiol (BD), and dimethyl succinate (DMS). Furthermore, we demonstrated the possibility to post-functionalize the new citronellol-based copolyester with different thiols applying the UV-mediated thiol-ene click reaction (Dondoni, 2008; Hoyle and Bowman, 2010). Since the introduction of additional functional groups into bio-polyesters represents an important tool to increase their potential for biomedical applications and, at the same time, is still a challenge (Parrish and Emrick, 2006; Williams, 2007; Jérôme and Lecomte, 2008; Pounder and Dove, 2010), our approach can be considered a new method to obtain easily functionalizable copolyesters.

\section{MATERIALS AND METHODS}

\section{General Remarks}

NMR spectra were taken at RT in $\mathrm{CDCl}_{3}$ at $300 \mathrm{MHz}\left({ }^{1} \mathrm{H}\right)$, and $75\left({ }^{13} \mathrm{C}\right)$, using, as internal standard, TMS $\left({ }^{1} \mathrm{H}\right.$ NMR: 0.000 ppm) or the central peak of $\mathrm{CDCl}_{3}\left({ }^{13} \mathrm{C}: 77.02 \mathrm{ppm}\right)$. Chemical 
shifts are reported in ppm ( $\delta$ scale). Peak assignments were made with the aid of gCOSY and gHSQC experiments. GC-MS analyses were carried out on a Hewlett Packard 5890 Series II, using a HP-1 column, coupled with a HP-5971A spectrometer (electron impact). Analysis conditions are as follows: flow (He) $0.9 \mathrm{~mL} / \mathrm{min}$; initial temperature $70^{\circ} \mathrm{C}$; initial time $2 \mathrm{~min}$; gradient temperature $20^{\circ} \mathrm{C} / \mathrm{min}$; final temperature $260^{\circ} \mathrm{C}$; final time $5 \mathrm{~min}$. Photooxidation reactions were performed with a white lamp (300 Osram ultra-vitalux $230 \mathrm{~V} \mathrm{AC).} \mathrm{Photoinduced} \mathrm{thiol-}$ ene reactions were performed with a Southern New England Ultraviolet Company Rayonet ${ }^{\circledR}$ apparatus equipped with 8 Iles Optical lamps (254 nm). TLC analyses were carried out on silica gel plates and viewed at UV $(254 \mathrm{~nm})$ and developed with Hanessian stain (dipping into a solution of $\left(\mathrm{NH}_{4}\right)_{4} \mathrm{MoO}_{4} .4 \mathrm{H}_{2} \mathrm{O}$ $(21 \mathrm{~g})$ and $\mathrm{Ce}\left(\mathrm{SO}_{4}\right)_{2} .4 \mathrm{H}_{2} \mathrm{O}(1 \mathrm{~g})$ in $\mathrm{H}_{2} \mathrm{SO}_{4}(31 \mathrm{ml})$ and $\mathrm{H}_{2} \mathrm{O}$ $(469 \mathrm{ml})$ and warming) or with $\mathrm{KMnO}_{4}$. Rf were measured after an elution of $7-9 \mathrm{~cm}$. Column chromatographies were done with the "flash" methodology using 220-400 mesh silica (Still et al., 1978). Petroleum ether $\left(40-60^{\circ} \mathrm{C}\right)$ is abbreviated as PE. Citronellol, thionin acetate, methylene blue and zeolite $\mathrm{Y}$, sodium $(\mathrm{NaY})$ were purchased from Alfa Aesar; triphenylphosphine, triphenylphosphine polymer-bound, $\mathrm{NaBH}_{4}$ and 2,2-dimethoxy2 -phenylacetophenone were purchased from Sigma Aldrich; $\alpha$ thioglycerol and cysteamine were purchased from TCI. All reagents are used as received.

Intrinsic viscosity was determined by using Ubbelohde type viscometer 31 13/Ic (diameter $0.84 \mathrm{~mm}$ ) at $30^{\circ} \mathrm{C}$. Four different polymer $/ \mathrm{CHCl}_{3}$ solutions were tested $(0.80,0.69,0.58$, and $0.47 \mathrm{~g} / \mathrm{dl})$.

TGA analysis was carried out with a Perkin Elmer TGA7 Instrument under $\mathrm{N}_{2}$ flow $(40 \mathrm{ml} / \mathrm{min}$ ) by heating from 40 to $800^{\circ} \mathrm{C}$ at $10^{\circ} \mathrm{C} / \mathrm{min}$.

DSC measurements were conducted with a Perkin Elmer DSC7 Instrument. The external block temperature control was set at $-120^{\circ} \mathrm{C}$. The samples, about $10 \mathrm{mg}$, were encapsulated in aluminum pans and subjected to the following thermal treatment: i) heating from $-70^{\circ} \mathrm{C}$ to a temperature $40^{\circ} \mathrm{C}$ above the melting, $20^{\circ} \mathrm{C} / \mathrm{min}$; ii) cooling to $-70^{\circ} \mathrm{C}, 100^{\circ} \mathrm{C} / \mathrm{min}$; iii) heating from $-70^{\circ} \mathrm{C}$ to a temperature $40^{\circ} \mathrm{C}$ above the melting, $20^{\circ} \mathrm{C} / \mathrm{min}$.

Wide angle X-ray scattering (WAXS) measurements were carried out with a PANalytical X'PertPro diffractometer equipped with a fast solid state X'Celerator detector and a copper target $(\lambda$ $=0.15418 \mathrm{~nm}$ ).

Stress-strain measurements were performed using an Instron 5966 tensile testing machine equipped with a $500 \mathrm{~N}$ load cell controlled by computer. Rectangular films $\left(5 \times 20 \mathrm{~mm}^{2}\right)$ were employed and $10 \mathrm{~mm} / \mathrm{min}$ crosshead speed was adopted.

Fourier-transform InfraRed (FTIR) spectra of PBS, copolymers and functionalized copolymer films were collected at RT, by means of a Bruker IFS66 spectrometer equipped with an attenuated total reflectance accessory (ATR). A total of 32 spectra in the spectral range $500-4,000 \mathrm{~cm}^{-1}$ with a resolution of $4 \mathrm{~cm}^{-1}$ were acquired for each sample.

\section{Photooxidation of Citronellol in Solution}

A solution of 1 ( $500 \mathrm{mg}, 3.20 \mathrm{mmol})$ and Rose Bengal $(32 \mathrm{mg}$, $0.032 \mathrm{mmol}$ ) in $\mathrm{MeOH}(8 \mathrm{~mL})$ was purged with air (dried on silica rods) and irradiated with white light. After consumption of the starting material ( $8 \mathrm{~h}$, monitoring by TLC analysis), the mixture was cooled at $0^{\circ} \mathrm{C}$, and $\mathrm{NaBH}_{4}(157 \mathrm{mg}, 4.16 \mathrm{mmol})$ was added. After complete reduction of the hydroperoxides 2 and 3 ( $5 \mathrm{~h}$, monitoring by TLC analysis), the reaction mixture was poured into $5 \%$ aqueous $\left(\mathrm{NH}_{4}\right) \mathrm{H}_{2} \mathrm{PO}_{4}$ and $1 \mathrm{M} \mathrm{HCl}(5: 1,15 \mathrm{~mL})$, $\mathrm{MeOH}$ was evaporated, and the aqueous phases extracted twice with ethyl acetate. The organic phases were dried with $\mathrm{Na}_{2} \mathrm{SO}_{4}$, filtered and evaporated. The regioisomeric ratio was determined by ${ }^{1} \mathrm{H}$ NMR of the crude product $(4: 5=49: 51)$. The crude was purified by column chromatography (PE/AcOEt from 3:2 to 1:1) affording 4 and 5 as a colorless oil (394 mg, 72\%). Diol 4 (2 diast.): ${ }^{1} \mathrm{H}$ NMR: $\delta_{\mathrm{H}} 4.97-4.90\left(2 \mathrm{H}, \mathrm{m}, 1 \mathrm{H}\right.$ of $\left.\mathrm{CH}_{2}=\right), 4.88-4.81(2 \mathrm{H}$, $\mathrm{m}, 1 \mathrm{H}$ of $\left.\mathrm{CH}_{2}=\right), 4.05\left(2 \mathrm{H}, \mathrm{td},{ }^{3} \mathrm{~J}=6.4,3.4 \mathrm{~Hz}, \mathrm{CH}\right), 3.77-3.39$ $\left(4 \mathrm{H}, \mathrm{m}, \mathrm{CH}_{2}\right), 1.73\left(6 \mathrm{H}, \mathrm{s}, \mathrm{CH}_{3}\right), 1.67-1.05\left(18 \mathrm{H}, \mathrm{m}, 3 \mathrm{CH}_{2}, 2\right.$ $\mathrm{OH}, \mathrm{CH}), 0.92\left(6 \mathrm{H}, \mathrm{d},{ }^{3} \mathrm{~J}=6.6 \mathrm{~Hz}, \mathrm{CH}_{3}\right) ;{ }^{13} \mathrm{C}$ NMR: $\delta_{\mathrm{C}} 147.6$ (C quat), 147.5 (C quat), $111.1\left(\mathrm{CH}_{2}\right), 110.9\left(\mathrm{CH}_{2}\right), 76.3(\mathrm{CH})$, $75.9(\mathrm{CH}), 60.9\left(2 \mathrm{CH}_{2}\right), 39.7\left(2 \mathrm{CH}_{2}\right), 32.7\left(\mathrm{CH}_{2}\right), 32.5\left(\mathrm{CH}_{2}\right)$, $32.2\left(\mathrm{CH}_{2}\right), 32.1\left(\mathrm{CH}_{2}\right), 29.5(\mathrm{CH}), 29.2(\mathrm{CH}), 19.6\left(2 \mathrm{CH}_{3}\right), 17.6$ $\left(\mathrm{CH}_{3}\right), 17.4\left(\mathrm{CH}_{3}\right)$; GC-MS: $6.04 \mathrm{~min}, \mathrm{~m} / \mathrm{z}(\%): 154(0.69)\left[\mathrm{M}^{+}\right.$ $\left.\mathrm{H}_{2} \mathrm{O}\right], 99$ (6.9), 86 (16), 84 (11), 83 (10), 72 (20), 71 (100), 70 (8.7), 69 (31), 68 (8.0), 67 (9.2), 58 (12), 57 (12), 56 (27), 55 (31), 43 (40), 42 (8.1), 41 (36), 39 (11); Diol 5: ${ }^{1} \mathrm{H}$ NMR: $\delta_{\mathrm{H}} 5.67-5.54(2 \mathrm{H}, \mathrm{m}$, $2 \mathrm{CH}=), 3.80-3.60\left(2 \mathrm{H}, \mathrm{m}, \mathrm{CH}_{2}\right), 2.05\left(1 \mathrm{H}, \mathrm{dt},{ }^{3} \mathrm{~J}=5.7,4.2 \mathrm{~Hz}\right.$, $1 \mathrm{H}$ of $\left.\mathrm{CH}_{2}\right), 1.90\left(1 \mathrm{H}, \mathrm{ddd},{ }^{3} \mathrm{~J}=9.5,6.5,4.3 \mathrm{~Hz}, 1 \mathrm{H}\right.$ of $\left.\mathrm{CH}_{2}\right), 1.75$ - $1.57\left(4 \mathrm{H}, \mathrm{m}, 2 \mathrm{OH}, \mathrm{CH}_{2}\right), 1.42\left(1 \mathrm{H}, \mathrm{dd},{ }^{3} J=11.1,4.2 \mathrm{~Hz}, \mathrm{CH}\right)$, $1.31\left(6 \mathrm{H}, \mathrm{s}, 2 \mathrm{CH}_{3}\right), 0.91\left(3 \mathrm{H}, \mathrm{t},{ }^{3} \mathrm{~J}=4.7 \mathrm{~Hz}, \mathrm{CH}_{3}\right) ;{ }^{13} \mathrm{C} \mathrm{NMR}: \delta_{\mathrm{C}}$ $139.6(\mathrm{CH}), 125.2(\mathrm{CH}), 70.6\left(\mathrm{C}\right.$ quat), $60.8\left(\mathrm{CH}_{2}\right), 39.6\left(\mathrm{CH}_{2}\right)$, $39.2\left(\mathrm{CH}_{2}\right), 29.8(\mathrm{CH}), 29.76\left(\mathrm{CH}_{3}\right), 29.68\left(\mathrm{CH}_{3}\right), 19.6\left(\mathrm{CH}_{3}\right)$; GC-MS: $5.58 \mathrm{~min}, \mathrm{~m} / \mathrm{z}(\%): 172(0.02)\left[\mathrm{M}^{+}\right], 139$ (39), 121 (11), 109 (9.5), 95 (8.6), 93 (5.3), 85 (17), 84 (6.4), 83 (8.9), 82 (5.5), 81 (14), 71 (19), 69 (29), 67 (16), 59 (13), 57 (7.2), 55 (23), 53 (5.2), 43 (100), 41 (21), $38.9(8.9)$.

\section{Loading Dye Within Zeolite}

Supported photosensitizers on zeolite were prepared following a literature procedure (Shailaja et al., 2000): to a solution of the opportune photosensitizer ( 5 or $25 \mathrm{mg}$ ) in deionized water $(250 \mathrm{~mL}), \mathrm{NaY}(5.00 \mathrm{gr})$ is added. The mixture is mixed trough an orbital shaker for $24 \mathrm{~h}$ at room temperature in the dark. Then, the mixture is filtered, washed with deionized water and dried overnight at $110^{\circ} \mathrm{C}$. During the cation exchange procedure, we assume the complete adsorption of the dye into the zeolite, although the obvious loss of organic molecule during washes can reduce the amount of the dye included into the final material.

\section{Photooxidation of Citronellol Using Thionine/NaY Photosensitizer}

To a solution of $\mathbf{1}(100 \mathrm{mg}, 0.64 \mathrm{mmol})$ in hexane $(9 \mathrm{~mL})$ $\mathrm{TH} / \mathrm{NaY}$ (1.8 gr, $0.005 \% \mathrm{w} / \mathrm{w}$ ) was added and the mixture was stirred in the dark for $15 \mathrm{~min}$. Then the mixture was evaporated and dried using high vacuum pump for $30 \mathrm{~min}$ in the dark. The solid obtained was transferred on the suitable flask and connected to reactor (see Supplementary Material for details). The rotating mixture was purged with air (dried on silica rods) and irradiated with white light. After consumption of the starting material (19h, monitoring by TLC analysis), the solid material was suspended in acetonitrile $(9 \mathrm{~mL})$ and 
stirred for $15 \mathrm{~min}$ in the dark. The mixture was then filtrated through a sintered funnel, and the liquid was treated with $\mathrm{Ph}_{3} \mathrm{P}$ (251 mg, $0.96 \mathrm{mmol}$ ). After complete reduction of the hydroperoxides 2 and $\mathbf{3}$ ( $1 \mathrm{~h}$, monitoring by TLC analysis), the reaction mixture was evaporated, and the crude was purified by column chromatography (PE/AcOEt 1:1) affording 4 and 5 as a colorless oil (102 $\mathrm{mg}, 93 \%)$. The regioisomeric ratio was determined by ${ }^{1} \mathrm{H}$ NMR of the crude product $(4: 5=82: 18)$.

\section{Recycling Tests of $\mathrm{TH} / \mathrm{NaY}$}

To a solution of $\mathbf{1}(480 \mathrm{mg}, 3.07 \mathrm{mmol})$ in hexane $(44 \mathrm{~mL})$ $\mathrm{TH} / \mathrm{NaY}(8.7 \mathrm{gr}, 0.005 \% \mathrm{w} / \mathrm{w})$ was added and the mixture was stirred in the dark for $15 \mathrm{~min}$. Then the mixture was evaporated and dried using high vacuum pump for $30 \mathrm{~min}$ in the dark. The solid obtained was transferred on the suitable flask and connected to reactor (see Supplementary Material for details). The rotating mixture was purged with air (dried on silica rods) and irradiated with white light. After consumption of the starting material ( $24 \mathrm{~h}$, monitoring by TLC analysis), the solid material was suspended in acetonitrile $(50 \mathrm{~mL})$ and stirred for $15 \mathrm{~min}$ in the dark. The mixture was then filtrated through a sintered funnel and the liquid was treated with supported $\mathrm{Ph}_{3} \mathrm{P}(1.37$ gr, $4.11 \mathrm{mmol}$, loading $3 \mathrm{mmol} / \mathrm{gr})$. After complete reduction of the hydroperoxides 2 and 3 (3 days, monitoring by TLC analysis), the reaction mixture was filtrated on celite washing with $\mathrm{CH}_{3} \mathrm{CN}$ ( $5 \mathrm{~mL}$ ), affording 4 and 5 as a colorless oil (416 mg, $78 \%)$. The regioisomeric ratio was determined by ${ }^{1} \mathrm{H}$ NMR of the crude product $(4: 5=89: 11)$. The catalyst $\mathrm{TH} / \mathrm{NaY}$ was dried at $110^{\circ} \mathrm{C}$ overnight and used for other two times with the following results: second run conversion $100 \%$, ratio $4: 5=77: 23$; third run conversion $100 \%$, ratio $4: 5=91: 9$.

\section{Synthesis of Copolyester 6}

Diol 4 (850 mg, $4.93 \mathrm{mmol}$ ), butanediol (BD) (667 mg, 7.40 $\mathrm{mmol})$, dimethyl succinate (DMS) (1.38 g, $9.49 \mathrm{mmol})$, together with Titanium(IV) butoxide (TBT) $(9.50 \mathrm{mg}, 0.078 \mathrm{mmol})$ were added in a stirred glass reactor with a thermostatted salt bath. In the first stage, the temperature was raised to $180^{\circ} \mathrm{C}$, keeping the system under $\mathrm{N}_{2}$ atmosphere for $3 \mathrm{~h}$. In the second stage, the temperature was slowly increased to $220^{\circ} \mathrm{C}$, and the pressure was gradually reduced to $0.1 \mathrm{mbar}$. After $3 \mathrm{~h}$, the reaction product was discharged from the reactor and cooled down to room temperature. A light yellow solid was obtained with $89 \%$ yield (1.70 g, $8.51 \mathrm{mmol})$.

\section{Synthesis of Copolyester 7}

Mix of diols 4 and 5 (300 mg, $1.74 \mathrm{mmol}$ ), butanediol (BD) (366 mg, $4.06 \mathrm{mmol}$ ), dimethyl succinate (DMS) (651 mg, 4.06 $\mathrm{mmol})$, together with Titanium(IV) butoxide (TBT) $(4.75 \mathrm{mg}$, $0.039 \mathrm{mmol}$ ) were added in a stirred glass reactor with a thermostatted salt bath. In the first stage, the temperature was raised to $180^{\circ} \mathrm{C}$, keeping the system under $\mathrm{N} 2$ atmosphere for $3 \mathrm{~h}$. In the second stage, the temperature was kept constant at $180^{\circ} \mathrm{C}$, and the pressure was gradually reduced to 0.1 mbar. After $3 \mathrm{~h}$, the reaction product was discharged from the reactor and cooled down to room temperature. A light yellow solid was obtained with $64 \%$ yield $(570 \mathrm{mg}, 2.85 \mathrm{mmol}$ ).

\section{Synthesis of Functionalized Copolyester 8}

Copolyester 6 (201 mg, loading $\mathrm{C}=\mathrm{C} \quad 1.39 \mathrm{mmol} / \mathrm{gr})$ was dissolved in $1 \mathrm{~mL} \mathrm{CH}_{3} \mathrm{CN}$ in a quartz vial, and $\alpha$-thioglycerol (121 $\mu \mathrm{L}, 1.40 \mathrm{mmol}$ ) was added. The vial was sealed with a septum, degassed by sparging for $5 \mathrm{~min}$, and exposed to a handheld UV lamp $(\lambda=254 \mathrm{~nm})$ for $7 \mathrm{~h}$. The conversion was determined by ${ }^{1} \mathrm{H}$ NMR integration of the terminal double bonds. The crude solution was then precipitated into cold $\mathrm{CH}_{3} \mathrm{CN} / \mathrm{H}_{2} \mathrm{O}$ solution $(1: 1,1.5 \mathrm{~mL} * 2)$ to yield the functional copolyester 8 (151 mg, 75\%) as yellow solid.

\section{Synthesis of Functionalized Copolyester 9}

Copolyester 6 (194 mg, loading $\mathrm{C}=\mathrm{C} \quad 1.70 \mathrm{mmol} / \mathrm{gr})$ was dissolved in $1 \mathrm{~mL} \mathrm{CH}{ }_{3} \mathrm{CN}$ in a quartz vial, and 2-(Bocamino)ethanethiol (192 mg, $1.08 \mathrm{mmol}$ ) and DMPA (4.6 mg, 0.02 mmol) were added. The vial was sealed with a septum, degassed by sparging for $5 \mathrm{~min}$, and exposed to a handheld UV lamp $(\lambda=$ $254 \mathrm{~nm}$ ) for $23 \mathrm{~h}$. The conversion was determined by ${ }^{1} \mathrm{H} \mathrm{NMR}$ integration of the terminal double bonds. The crude solution was then precipitated into cold $\mathrm{CH}_{3} \mathrm{CN} / \mathrm{H}_{2} \mathrm{O}$ solution $(1: 1,3 \mathrm{~mL}$ * 2) to yield the functional copolyester 9 (204 mg, 90\%) as yellow solid.

\section{RESULTS AND DISCUSSION}

In this section, the results obtained were presented and discussed following this order: (1) optimization of the photooxidation of citronellol using zeolite supported-photosensitizer was reported with the aim to improve the yield and the regioselectivity of the process (section optimization of the regioselective photooxidation of citronellol); (2) secondly, the scalability and recyclability of the zeolite supported-photosensitizer (Thionine$\mathrm{NaY}$ ) were demonstrated [section scalability and recyclability of the zeolite supported-photosensitizer (Thionine-NaY)]; (3) the purified diol $\mathbf{4}$ and the unpurified mixture of diols $\mathbf{4 + 5}$ were employed for the preparation of two $\mathrm{C}-\mathrm{C}$ double bond containing polyesters, which have been properly characterized (section synthesis and characterization of citronellol-containing biopolyesters 6 and 7); (4) finally, we demonstrated the possibility to functionalize these $\mathrm{C}-\mathrm{C}$ double bond containing polyesters using UV promoted thiol-ene click reaction (section synthesis of functionalized bio-polyesters 8 and 9 using UV-mediated thiol-ene reaction).

\section{Optimization of the Regioselective Photooxidation of Citronellol}

We started comparing the photooxygenation reaction of (rac-)citronellol $\mathbf{1}$ with different sensitizers in homogeneous conditions and with zeolites (Table 1). As expected, complete conversion into a 1:1 mixture of regioisomers was obtained treating 1 with $1 \% \mathrm{RB}$, air and white light (entry 2), while only starting material was recovered in absence of the photosensitizer (entry 1). Similar results were obtained using methylene blue $(\mathrm{MB})$ and thionine acetate (TH) in place of RB (entries 3 and 4). The experiments with zeolites were carried out after adsorption of the photosensitizers onto commercially available zeolite (NaY) followed by a cation-exchange process (Shailaja et al., 2000). 
TABLE 1 | Optimization of the regioselective photosensitized oxidation of citronellol $\mathbf{1}$ to give, after reduction, diols $\mathbf{4}$ and $\mathbf{5}$.

\begin{tabular}{|c|c|c|c|c|c|c|c|c|}
\hline Entry & Sensitizer & $\begin{array}{c}\text { Sens./zeolite } \\
{[\% \mathrm{w} / \mathrm{w}]}\end{array}$ & Solvent & $\begin{array}{c}1 \\
\text { [mg] }\end{array}$ & $\begin{array}{l}\text { Time } \\
\text { [h] }\end{array}$ & $\begin{array}{l}4: 5 \\
\text { ratio }^{[a]}\end{array}$ & $\begin{array}{l}\text { Conv. } \\
\%^{[b]}\end{array}$ & $\begin{array}{c}\text { Yield } \\
\%^{[c]} \\
4+5\end{array}$ \\
\hline 1 & $-[f]$ & - & $\mathrm{MeOH}$ & 500 & 8 & - & $0 \%$ & - \\
\hline $2^{[d]}$ & $\mathrm{RB}^{[\mathrm{g}]}$ & - & $\mathrm{MeOH}$ & 500 & 8 & $49: 51$ & $>95 \%$ & $72 \%$ \\
\hline $3^{[d]}$ & $\mathrm{MB}^{[\mathrm{g}]}$ & - & $\mathrm{MeOH}$ & 500 & 7 & $48: 52$ & $>90 \%$ & $63 \%$ \\
\hline $4^{[e]}$ & $\mathrm{TH}[\mathrm{g}]$ & - & $\mathrm{MeOH}$ & 100 & 18 & $46: 54$ & $>95 \%$ & $47 \%$ \\
\hline $5^{[\mathrm{e}]}$ & $\mathrm{MB} / \mathrm{NaY}$ & 0.001 & Hexane & 100 & 5.5 & $71: 29$ & $31 \%$ & - \\
\hline $6^{[\mathrm{e}]}$ & $\mathrm{MB} / \mathrm{NaY}$ & 0.001 & Cyclohexane & 220 & 19 & 70:30 & $71 \%$ & - \\
\hline $7^{[\mathrm{e}]}$ & $\mathrm{MB} / \mathrm{NaY} Y^{[\mathrm{h}]}$ & 0.001 & Neat & 20 & 7 & $81: 19$ & $98 \%$ & - \\
\hline $8^{[e]}$ & $\mathrm{MB} / \mathrm{NaY}[\mathrm{h}]$ & 0.001 & Neat & 100 & 29 & $82: 18$ & $51 \%$ & - \\
\hline$g^{[e]}$ & $\mathrm{MB} / \mathrm{NaY}$ & 0.005 & Neat & 100 & 14 & $79: 21$ & $56 \%$ & - \\
\hline $10^{[e]}$ & $\mathrm{TH} / \mathrm{NaY}^{[\mathrm{h}]}$ & 0.005 & Neat & 100 & 19 & $82: 18$ & $93 \%$ & $87 \%$ \\
\hline $11^{[\mathrm{e}]}$ & $\mathrm{TH} / \mathrm{NaY}{ }^{[\mathrm{h}]}$ & 0.005 & Neat & 50 & 15 & $82: 18$ & $92 \% \%$ & $66 \%$ \\
\hline $12^{[\mathrm{e}]}$ & $\mathrm{TH} / \mathrm{NaY}{ }^{[\mathrm{h}]}$ & 0.005 & Neat & 50 & 23 & 88:12 & $100 \%$ & $62 \%$ \\
\hline $13^{[\mathrm{e}]}$ & $\mathrm{TH} / \mathrm{NaY}{ }^{[\mathrm{h}]}$ & 0.005 & Neat & 50 & 48 & $99: 1$ & $100 \%$ & $41 \%$ \\
\hline $14^{[\mathrm{e}]}$ & $\mathrm{TH} / \mathrm{LiY}^{[\mathrm{h}]}$ & 0.005 & Neat & 50 & 15 & $99: 1$ & $92 \%$ & $31 \%$ \\
\hline $15^{[\mathrm{e}]}$ & $\mathrm{TH} / \mathrm{NaY} Y^{[\mathrm{h}]}$ & 0.005 & Neat & 480 & 24 & $89: 11$ & $88 \%$ & $78 \%$ \\
\hline
\end{tabular}

[a] The regioisomer ratio is calculated on the crude by ${ }^{1} \mathrm{H}-\mathrm{NMR}$ spectrum; [b] Conversion, defined as $[\mathbf{4}+\mathbf{5}] /$ starting $\mathbf{1}$, is calculated on the crude by ${ }^{1} \mathrm{H}-\mathrm{NMR}$; [C] Isolated yield after column chromatography; [d] $\mathrm{NaBH}_{4}$ (1.3 equiv) is used as reduction agent; [e] $P P h_{3}$ (1.5 equiv) is used as reducing agent; [f] Reaction conditions: 1, $\mathrm{MeOH}$, air, white light, $8 \mathrm{~h}$; [g] Typical reaction conditions: 1 (1 equiv), photosensitizer (0.01 equiv), $\mathrm{MeOH}$, air, white light, $8 \mathrm{~h}$; [h] Typical reaction conditions: $1(100 \mathrm{mg})$ in hexane $(9 \mathrm{~mL})$, zeolite-supported photosensitizer (1.8 gr), stirring $15 \mathrm{~min}$ in the dark; then evaporation of the solvent; the solid is treated with air, white light for $19 \mathrm{~h}$; the hydroperoxides are recovered adding $\mathrm{CH}_{3} \mathrm{CN}$ and subsequent filtration.

Since RB has never been immobilized on zeolites, we decided to study only the phenothiazine-based dyes (MB and $\mathrm{TH}$ ), that, on the other hand, are known to be efficient sensitizers in photooxygenation reactions conducted in the presence of zeolites (Wahlen et al., 2004). According with the literature (Ramamurthy et al., 1993; Hoppe et al., 1995), we assume that in our samples the dye molecules are uniformly distributed and remain at the centers of the supercages of $\mathrm{NaY}$. Actually, supercages of $\mathrm{NaY}$ are spherical and large enough to accommodate $\mathrm{TH}$ or $\mathrm{MB}$ (diameter of about $12 \AA$ and a freevolume of $827 \AA$ ).

Firstly, we carried out the photooxidation reaction in a hexane slurry of MB-NaY and $\mathbf{1}$ (entry 5), finding good regioselectivity for compound 4 , though with low conversion, compared to the reaction conducted in standard conditions (entry 3). Although the zeolites showed improved selectivity, this experimental protocol clearly affected the efficiency of the reaction due to the multiphasic nature of the system. Actually, four different entities must interact in order to achieve high selectivity and conversion rate: the solid phase, containing the supported photosensitizer, the liquid phase, containing the solvent and the substrate, the gas phase, containing oxygen, and finally the light.

When we tried to prolong the irradiation time, we serendipitously discovered that, upon unexpected evaporation of the solvent, the reaction proceeded overnight under neat conditions, with improved conversion and regioselectivity (entry

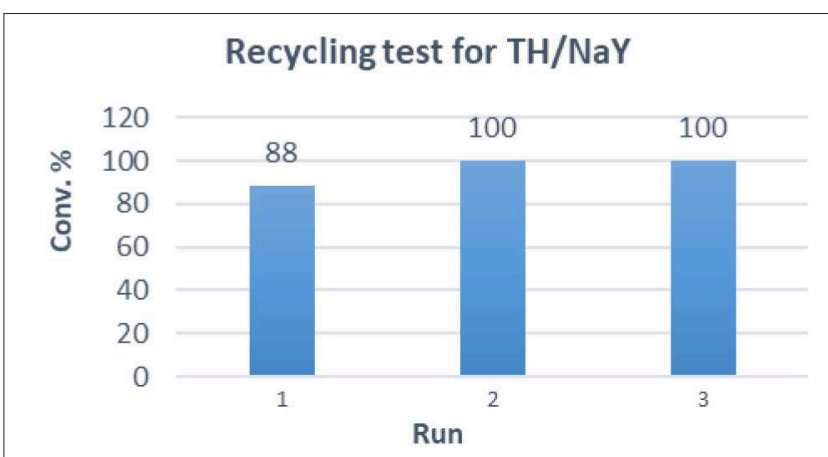

FIGURE 1 | Recycling tests of TH/NaY (loading 0.005\% w/w). Reaction conditions: 1 (480 mg), TH/NaY (8.7 gr), air, white light, $24 \mathrm{~h}$; then $\mathrm{CH}_{3} \mathrm{CN}$, supported- $\mathrm{PPh}_{3}$ (1.5 eq.), RT, 3 days.

6). Actually, in the absence of solvent, the MB-supported zeolite provides a microporous environment in which $\mathbf{1}$ may be adsorbed so to restrict its mobility, and may react with other local species, but is otherwise precluded from undergoing undesired further reactions (Rhodes, 2010).

Based on these results, we studied the photooxygenation in the absence of solvent, after adsorption of $\mathbf{1}$ onto the photosensitizer/zeolite system, varying the nature of the photosensitizer and the zeolite, the loading of the photosensitizer on zeolite and the loading of substrate respect on photosensitizersupported zeolite. Following the typical loading levels used in literature (Shailaja et al., 2000; Pace and Clennan, 2002) (0.9 g of $0.001 \% \mathrm{MB}-\mathrm{NaY}), 20 \mathrm{mg}$ of $\mathbf{1}$ was successfully converted with a remarkable 81:19 regioisomeric ratio (entry 7), while the conversion rapidly dropped when the amount of substrate was increased (entry 8).

Thus, we considered the possibility to use different loading levels, preparing both $0.005 \% \mathrm{MB}-\mathrm{NaY}$ and $\mathrm{TH}-\mathrm{NaY}$. The latter showed superior performance, leading to the products in excellent isolated yield and with very high regioisomeric ratio (entries 9-10). Thus, we choose TH-NaY with $0.005 \%$ loading level as the best photosensitizer system. Further experiments demonstrated that the irradiation time affects the yield, possibly due to the selective decomposition of the tertiary hydroperoxide 3 (see entries $11-13$ ). When $0.005 \%$ TH-LiY was used, extensive degradation appeared, as showed by low isolated yield (entry 14) (Kaanumalle et al., 2002). Although the more benign $\mathrm{NaBH}_{4}$ can be used for reducing hydroperoxides into alcohols, $\mathrm{PPh}_{3}$ allowed us to avoid a liquid-liquid extraction and thus the use of large amount of organic solvent.

\section{Scalability and Recyclability of the Zeolite Supported-Photosensitizer (Thionine-NaY)}

Finally, the scalability of our optimized procedure was evaluated, converting almost half gram of substrate (entry 15) with conversion, selectivity and isolated yield that seemed not to be affected by the scaling up (comparison with entry 10). The recyclability and stability of the $\mathrm{TH} / \mathrm{NaY}$ system was investigated by reusing the catalyst in consecutive catalytic runs (Figure 1). 

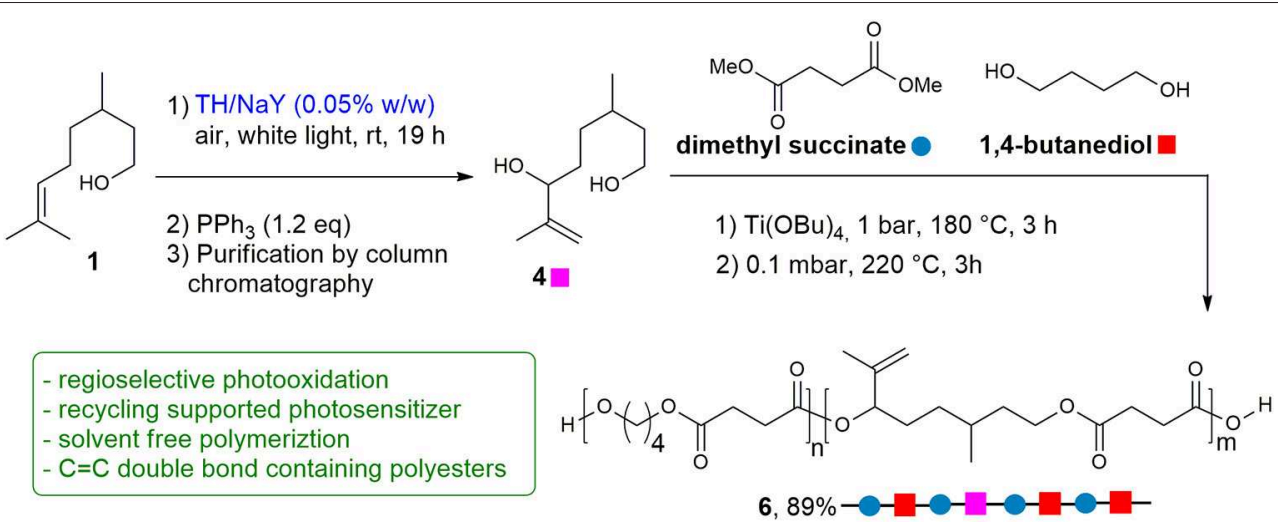

SCHEME 2 | Photosensitized transformation of citronellol 1 into diol 4, and polymerization process of functionalized co-polyester 6. Reaction conditions: (1) neat, $\mathrm{Ti}(\mathrm{OBu})_{4}\left(150 \mathrm{ppm}\right.$ of $\mathrm{Ti} / \mathrm{g}$ of polymer), $1 \mathrm{bar}, 180^{\circ} \mathrm{C}, 3 \mathrm{~h}$; (2) $0.1 \mathrm{mbar}, 220^{\circ} \mathrm{C}, 3 \mathrm{~h}$.

The results showed that substrate $\mathbf{1}$ can be nearly completely converted after $24 \mathrm{~h}$ of irradiation for at least three runs. After the run, $\mathrm{TH} / \mathrm{NaY}$ was simply recovered by filtration, washed with $\mathrm{CH}_{3} \mathrm{CN}$, and dried overnight at $110^{\circ} \mathrm{C}$. This protocol was found to be crucial, as the photosensitizer/zeolite system is very sensitive to humidity and a significant decrease of activity is generally observed when it is not properly dried.

\section{Synthesis and Characterization of Citronellol-Containing Biopolyesters 6 and 7}

To demonstrate whether the purified diol 4 could be used for polymerization, a random copolyester was synthesized by twostage polymerization, as summarized in Scheme 2, starting from: dimethyl succinate (DMS), butanediol (BD) and 4 . The reaction was carried out in bulk, starting from a $\mathrm{BD} / 4$ molar ratio of $60 / 40$. The glycols were added with a $30 \mathrm{~mol} \%$ excess with respect to DMS. The reaction was conducted in a stirred glass reactor with a thermostated salt bath. Temperature and torque were continuously recorded during the polymerization process. In the first stage, the temperature was raised to $180^{\circ} \mathrm{C}$, keeping the system under $\mathrm{N}_{2}$ atmosphere for $3 \mathrm{~h}$. In the second stage, the temperature was slowly increased to $220^{\circ} \mathrm{C}$, and the pressure was gradually reduced to $0.1 \mathrm{mbar}$. After $3 \mathrm{~h}$, the reaction product was discharged from the reactor and cooled down to room temperature. Applying these conditions, copolymer $\mathbf{6}$ was successfully obtained in $89 \%$ yield as a light yellow solid.

Through the optimization of the polymerization reaction conditions (time, temperature and catalyst amount) it was possible to overcome the problem relative to the lower reactivity of the secondary hydroxyl group of diol 4, avoiding at the same time crosslinking reactions involving the carbon double bond, which remains unchanged in the copolymer for subsequent ad hoc functionalization.

Encouraged by the above results, we decided to perform the polymerization process with the unpurified mixture of diols 4 and 5, directly obtained through the regioselectivephotosensitized oxidation and reduction process. The successful polymerization of the regioisomeric mixture, in fact, could avoid the chromatographic purification of $\mathbf{4}$, that represents a drawback in the development of a sustainable procedure. Nevertheless, the polymerization of the mixture is in principle particularly challenging as diol 5, beside the carbon double bond alike diol 4, contains an even less reactive tertiary hydroxyl group. First, polymerization was carried out using previous conditions, resulting not successful. On increasing $\mathrm{BD} / 4$ molar ratio to $70 / 30$ and keeping constant the temperature at $180^{\circ} \mathrm{C}$, a light yellow solid was obtained in $64 \%$ yield (Scheme 3 ).

It must be underlined that the proposed strategy represents a green method to transform a biobased substrate as citronellol into useful diols readily employed in the synthesis of a functionalized copolyester. Actually, the diols can be isolated after two simple filtrations, the first to recover $\mathbf{4}$ and $\mathbf{5}$ from the supported catalyst, the second to remove the supported reducing agent. Moreover, the catalyst can be conveniently reused after being dried, and the polymerization has been performed in bulk without solvents.

The thermal stability of the copolyesters were tested by thermogravimetric analysis (TGA). The thermogravimetric curves acquired under nitrogen flow (see Supplementary Material) shows a one-step weight loss with high temperature of maximum degradation rate $\left(\mathrm{T}_{\max }\right)$ (Table 2). The results show that the introduction of both $\mathbf{4}$ and 5 in the PBS main polymer chain does not compromise the good thermal stability of the neat homopolymer, being the $\mathrm{T}_{\max }$ of both copolymers even higher than $\mathrm{T}_{\max }$ of PBS.

The differential scanning calorimetry (DSC) heating curves (first and second scans after melt quenching) of the polymers under investigation (SI), with the relative calorimetric data (Table 2), show typical behavior of semicrystalline materials, being characterized by the glass-to-rubber transition step in heat capacity at low temperature, followed by an endothermic peak at higher temperature ascribable to the melting of the crystalline phase. A clear effect of copolymerization on both the position and the area of the melting peak can be evidenced. In particular, the introduction of the $\mathbf{4}$ and $\mathbf{5}$ subunits determines a decrease of melting temperature $\left(\mathrm{T}_{\mathrm{m}}\right)$, and of the associated enthalpy 


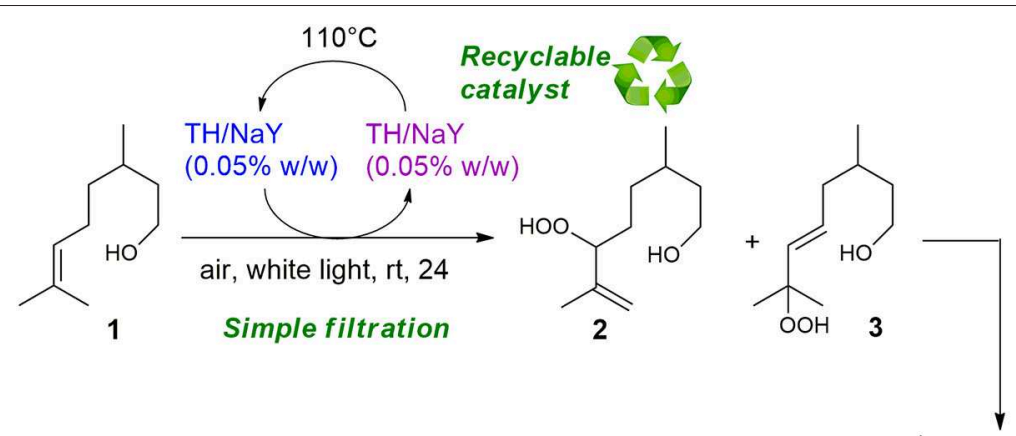

dimethyl succinate 1,4-butanediol

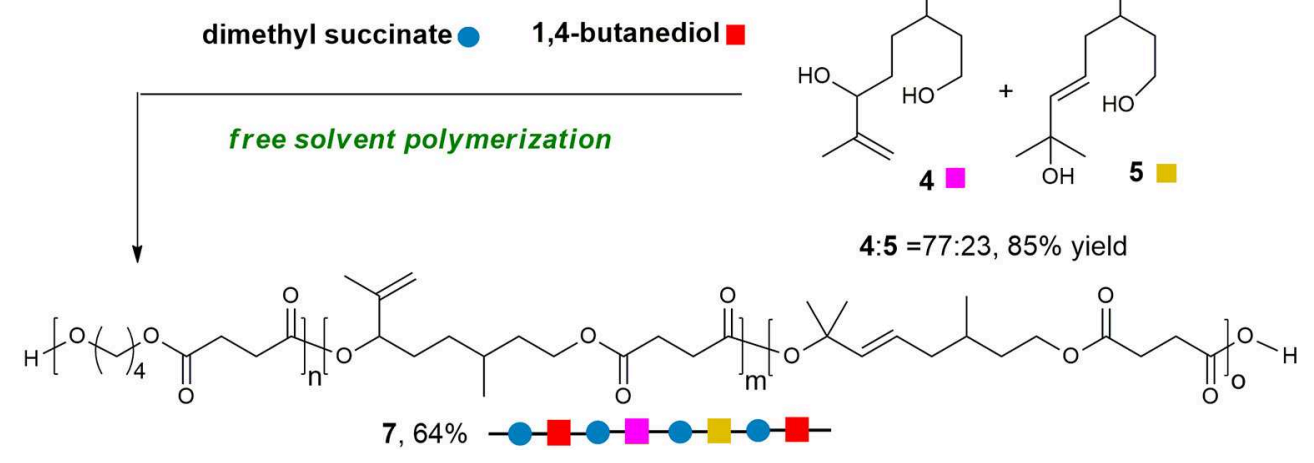

SCHEME 3 | Green synthesis of functionalized-copolyester $\mathbf{7}$ starting from citronellol $\mathbf{1}$

TABLE 2 | Molecular, structural, thermal and mechanical characterization data of PBS and copolymers $\mathbf{6 , 7}$ and $\mathbf{8}$.

\begin{tabular}{|c|c|c|c|c|c|}
\hline & & PBS & 6 & 7 & 8 \\
\hline \multirow[t]{2}{*}{${ }^{1} \mathrm{H}-\mathrm{NMR}$} & co-unit mol\% & - & 35 & $20+5$ & 27 \\
\hline & Yield [\%] & 96 & 89 & 63 & 75 \\
\hline Viscosity & I.V. [dl/g] & 1.48 & 0.79 & 1.06 & 0.67 \\
\hline TGA & $\mathrm{T}_{\max }\left[{ }^{\circ} \mathrm{C}\right]$ & 399 & 409 & 404 & 259,395 \\
\hline DSC & $\mathrm{T}_{\mathrm{m}}\left[{ }^{\circ} \mathrm{C}\right]$ & 115 & 53 & 85 & 51 \\
\hline I SCAN & $\Delta \mathrm{H}_{\mathrm{m}}[\mathrm{J} / \mathrm{g}]$ & 81 & 30 & 45 & 15 \\
\hline DSC & $\mathrm{T}_{\mathrm{g}}\left[{ }^{\circ} \mathrm{C}\right]$ & -34 & -33 & -34 & -16 \\
\hline \multirow[t]{5}{*}{ II SCAN } & $\Delta \mathrm{Cp}\left[\mathrm{J} / \mathrm{g}^{\star \circ} \mathrm{C}\right]$ & 0.212 & 0.481 & 0.223 & 0.573 \\
\hline & $\mathrm{T}_{\mathrm{C}}\left[{ }^{\circ} \mathrm{C}\right]$ & / & / & 23 & / \\
\hline & $\Delta \mathrm{H}_{\mathrm{C}}[\mathrm{J} / \mathrm{g}]$ & / & / & 12 & / \\
\hline & $\mathrm{T}_{\mathrm{m}}\left[{ }^{\circ} \mathrm{C}\right]$ & 115 & / & 85 & / \\
\hline & $\Delta \mathrm{H}_{\mathrm{m}}[\mathrm{J} / \mathrm{g}]$ & 62 & / & 40 & / \\
\hline WAXS & $X_{\mathrm{c}}[\%]$ & 40 & 16 & 27 & 11 \\
\hline \multirow[t]{3}{*}{ Tensile Test } & $\sigma_{\mathrm{b}}[\mathrm{MPa}]$ & $337 \pm 27$ & $2.3 \pm 0.8$ & $7 \pm 1$ & n.d \\
\hline & $\varepsilon_{\mathrm{b}}[\%]$ & $4 \pm 1$ & $15 \pm 2$ & $5 \pm 1$ & n.d \\
\hline & $\mathrm{E}$ [MPa] & $301 \pm 2$ & $26 \pm 5$ & $147 \pm 16$ & n.d \\
\hline
\end{tabular}

$\left(\Delta \mathrm{H}_{\mathrm{m}}\right)$. This reduction seems to depend only on the subunit amount and not on their nature. As a matter of fact, the $\mathrm{T}_{\mathrm{m}}$ decrease is higher in $\mathbf{6}$, containing $35 \mathrm{~mol} \%$ of $\mathbf{4}$, than in $\mathbf{7}$, in which two different co-units $(20$ and $5 \mathrm{~mol} \%$ of 4 and $\mathbf{5}$, respectively) have been introduced. This result can be considered as indirect evidence that the crystalline phase present in the copolymers is the same as the pure PBS, and the comonomeric units are completely rejected in the amorphous regions.
The amount of co-units also plays a role in the crystallization capability, as confirmed by the second scan traces. In fact, as one can see from Table 2, the high crystallization capability of PBS polymer chains is reduced in 7 containing $25 \mathrm{~mol} \%$ of diols and is completely depressed in 6 by adding $35 \mathrm{~mol} \%$ of 4. Copolyester 7, indeed, shows a more intense glass transition step with respect to PBS homopolymer, indicating higher amount of amorphous phase. The sample is able to crystallize during the heating scan as evidenced by the exothermic peak at $23^{\circ} \mathrm{C}$ ("cold-crystallization"). Nevertheless, being $\Delta \mathrm{H}_{\mathrm{m}}>\Delta \mathrm{H}_{\mathrm{c}}$, the crystallization of 7 also partially occurs during the cooling step. On the other hand, the DSC second scan curve of $\mathbf{6}$, evidenced that the introduction of $35 \mathrm{~mol} \%$ of diol 4 allows to suppress crystallization, obtaining a completely amorphous material upon quenching, preventing the formation of crystal during the subsequent heating step. In fact, only the glass transition phenomenon can be detected.

Moreover, as suggested by the constant $\mathrm{T}_{\mathrm{g}}$ values in all the three samples, the presence of $\mathbf{4}$ and $\mathbf{5}$ along the polymer backbone does not change the chain mobility.

The copolyesters films were also subjected to WAXS characterization to determine the crystal lattice. The X-ray patterns (SI) and the relative crystallinity degree $\left(\mathrm{X}_{\mathrm{c}}\right)$ are reported (Table 2). In agreement with the calorimetric results, the crystalline phase found in both the copolyesters corresponds to the $\alpha$-PBS lattice with the characteristic peaks located at $19.6^{\circ}, 22.5^{\circ}, 21.7^{\circ}, 25^{\circ}$ and $45^{\circ}$ (see Supplementary Material). Moreover, diffractometric peak position does not change with copolymerization, suggesting the rejection of the comonomeric units in the amorphous phase. The diffractometric results are in 


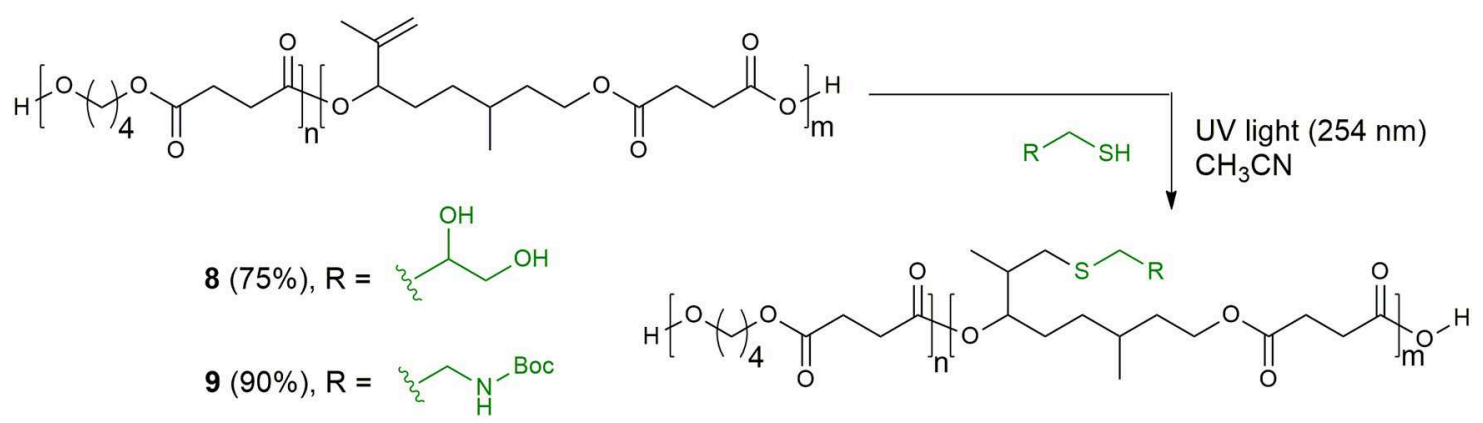

SCHEME 4 | Thiol-ene modification of the citronellol-based copolyester of poly(butylene succinate) with thioglycerol and N-Boc-cysteamine.

line with the calorimetric ones, also in relation to a reduction of the quantity of crystalline domains. Again, the higher the amount of co-units, the lower the crystallinity degree.

The polymer films obtained by compression molding were subjected to stress-strain measurements to evaluate their mechanical response (Table 2 and Supplementary Material). The results obtained evidenced a reduction of elastic modulus (E) and tensile strength $\left(\sigma_{\mathrm{b}}\right)$ in both copolymers. In particular, with respect to PBS, E is halved in 7 and is five times lower for 6 .

The trend observed can be explained on the basis of the crystallinity decrease. As well known, both $\mathrm{E}$ and $\sigma_{\mathrm{b}}$ are directly dependent on the amorphous/crystals phase ratio, in particular a reduction of ordered regions determines the decrease of the elastic modulus and tensile strength. As concerns, the elongation at break $\left(\varepsilon_{\mathrm{b}}\right)$, there is an increase from $4 \%$ for PBS film to $22 \%$ in the less crystalline copolyester $\mathbf{6}$, while no significant effect was evidenced for 7 , which shows the same elongation at break of the homopolymer. Again, the dissimilar behavior can be related to the different degree of crystallinity, being this quantity higher for 7 .

\section{Synthesis of Functionalized Bio-Polyesters 8 and 9 Using UV-Mediated Thiol-Ene Reaction}

Finally, we have investigated the possibility to functionalize the unsaturated copolyester $\mathbf{6}$ exploiting the highly efficient thiolene coupling reaction. The great success of this reaction in polymer and material science is due to its orthogonality to a wide range of functional groups and to the robustness of the ligation motif between substrates thanks to the stability of the thioether linkage in a wide range of chemical environments (Lowe, 2010). Thus, we carried out the reaction between polymer 6 and thioglycerol, using UV irradiation and acetonitrile, monitoring the conversion of the substrate by ${ }^{1} \mathrm{H}-\mathrm{NMR}$ analysis. After $6 \mathrm{~h}$ the double bond was quantitatively converted and the functionalized copolyester $\mathbf{8}$ was recovered by precipitation in good yield. When $\mathrm{N}$-Boc-cysteamine was employed as thiol component, the addition of a small amount of photoinitiator 2,2dimethoxyphenylacetophenone (DMPA, 0.05 eq) showed better results (Scheme 4).
While some examples of post-functionalized polyesters obtained combining ring-opening polymerization (ROP) and thiol-ene click chemistry recently appeared in literature (Darcos et al., 2012; Pelegri-O'Day et al., 2017; Guindani et al., 2019), to the best of our knowledge, this is one of the rare examples of combination of polycondensation reaction and thiol-ene click chemistry to prepare functionalized biobased degradable polyesters, and the first example employing isopropenyl moiety as reactive alkene substrate (Kolb and Meier, 2013; Trotta et al., 2019).

The successful incorporation of the two thiols into the polymer chains of citronellol-based copolyester was verified by IFT-IR measurements of the polymer films after purification. The ATR-FT-IR spectra of the functionalized polymers are shown in the Supporting Information (Figure S9) and compared to PBS homopolymer and copolyesters 6 and 7. The inclusion of thioglycerol in polymer $\mathbf{8}$ can be deduced by the appearance of broad IR absorption band peaked around 3,450 $\mathrm{cm}^{-1}$, attributed to the stretching vibration of $\mathrm{O}-\mathrm{H}$ groups. On the other hand, the functionalization with $\mathrm{N}$-Boc-cysteamine results in two characteristic bands related to $\mathrm{N}-\mathrm{H}$ stretching (around 3,370 $\left.\mathrm{cm}^{-1}\right)$ and bending $\left(1,510 \mathrm{~cm}^{-1}\right.$, associated to $\mathrm{NH}$ bending trans to carbonyl oxygen).

The functionalized copolyester $\mathbf{8}$ has been subjected to further characterization. As one can see from the data reported in Table 2, the functionalization determines a $15 \%$ reduction of intrinsic viscosity (proportional to the polymer molar mass) that however keeps quite high. As concerns the thermal stability, a two-step degradation can be evidenced: the first weight loss takes place at $259^{\circ} \mathrm{C}$ (related to the degradation of the co-units) and the second one at $395^{\circ} \mathrm{C}$ (ascribable to the degradation of BS sequences).

Calorimetric measurements highlight the introduction of -S$\mathrm{R}$ branches provides a further reduction of the crystalline portion ( $\Delta \mathrm{H}_{\mathrm{m}}$ decreases) with respect to the amorphous one $(\Delta \mathrm{Cp}$ increases). In addition, $-\mathrm{S}-\mathrm{R}$ branches determines a reduction of chain mobility as indicated by the rise in $\mathrm{T}_{\mathrm{g}}$.

\section{CONCLUSIONS}

In the present work, we have successfully applied the dyesensitized photooxidation reaction as sustainable route 
for the regioselective conversion of a naturally occurring monoterpenoid, citronellol, into diols 4 and 5. The two-step sequence involves a photooxidation reaction performed in neat conditions using air, visible light and zeolite supportedThionine as unique reagents, and secondly a reduction step mediated by a phosphine, to give 4 with high regioselectivity. The zeolite supported photosensitizer can be recovered and reused as catalyst for at least 3 times. Both the purified diol 4, and the mixture of $\mathbf{4}$ and 5, have been successfully used in a polycondensation reaction generating two copolyesters of poly(butylene succinate) (PBS). The introduction of the citronellol-based building block produced a more flexible and functionalizable material, providing an efficient way to modulate the final polymer properties, such as hydrophilicity, crystallinity, elasticity, and, eventually, bioactivity. The presence of the $\mathrm{C}=\mathrm{C}$ double bond on the polymer has been exploited for the subsequent functionalizations, using a UV promoted thiol-ene click reaction. Two different functionalized copolyesters were synthetized and partially characterized. The application of these materials for controlled-drug delivery systems is underway in our laboratory and will be presented in due course.

\section{DATA AVAILABILITY STATEMENT}

All datasets generated for this study are included in the article/Supplementary Material.

\section{REFERENCES}

Alberti, M. N., and Orfanopoulos, M. (2010). Recent mechanistic insights in the singlet oxygen ene reaction. Synlett 2010, 999-1026. doi: $10.1055 / \mathrm{s}-0029-1219790$

Anselmo, M., Basso, A., and Moni, L. (2019). "Photoorganocatalysis in Flow," in Photoorganocatalysis in Organic Synthesis, eds M. Fagnoni, S. Protti, and D. Ravelli (World Scientific (Europe)), 519-558. doi: 10.1142/9781786346056_0012

Bouamri, M. E., Gorrichon, J. P., Braun, A. M., and Oliveros, E. (1991). The reactivity of citronellol and $\alpha$-thujene with singlet oxygen. Rate constants of chemical reaction and physical quenching*. Photochem. Photobiol. 54, 619-623. doi: 10.1111/j.1751-1097.1991.tb02065.x

Byrne, C. M., Allen, S. D., Lobkovsky, E. B., and Coates, G. W. (2004). Alternating copolymerization of limonene oxide and carbon dioxide. J. Am. Chem. Soc. 126, 11404-11405. doi: 10.1021/ja0472580

Chen, Y.-Z., Wu, L.-Z., Zhang, L.-P., and Tung, C.-H. (2005). Confined space-controlled hydroperoxidation of trisubstituted alkenes adsorbed on pentasil zeolites. J. Org. Chem. 70, 4676-4681. doi: 10.1021/jo05 $0081 \mathrm{n}$

Clark, C. A., Lee, D. S., Pickering, S. J., Poliakoff, M., and George, M. W. (2016). A simple and versatile reactor for photochemistry. Org. Process Res. Dev. 20, 1792-1798. doi: 10.1021/acs.oprd.6b 00257

Corma, A., Iborra, S., and Velty, A. (2007). Chemical routes for the transformation of biomass into chemicals. Chem. Rev. 107, 2411-2502. doi: 10.1021/cr050989d

Darcos, V., Antoniacomi, S., Paniagua, C., and Coudane, J. (2012). Cationic polyesters bearing pendent amino groups prepared by thiol-ene chemistry. Polym. Chem. 3, 362-368. doi: 10.1039/C1PY00414J

Dondoni, A. (2008). The emergence of thiol-ene coupling as a click process for materials and bioorganic chemistry. Angew. Chem. Int. Ed. 47, 8995-8997. doi: $10.1002 /$ anie. 200802516

\section{AUTHOR CONTRIBUTIONS}

The manuscript was written through contributions of all authors. All authors have given approval to the final version of the manuscript.

\section{FUNDING}

This work has received funding from the European Union's Horizon 2020 research and innovation programme under the Marie Sklodowska-Curie grant agreement No. 778092.

\section{SUPPLEMENTARY MATERIAL}

The Supplementary Material for this article can be found online at: https://www.frontiersin.org/articles/10.3389/fchem. 2020.00085/full\#supplementary-material

Photographs of reactors and lamp used for photosensitized oxidation of citronellol, preparation of LiY zeolites from $\mathrm{NaY}$, structure and composition of copolyesters $\mathbf{6 , 7}$ and $\mathbf{8}$ verified via ${ }^{1} \mathrm{H}-\mathrm{NMR}$ spectroscopy, thermogravimetric curves of copolyesters 6 and 7, DSC heating curves of copolyesters 6 and 7, WAXS characterization of copolymers 6 and 7, evaluation of the mechanical properties of copolymers 6 and $7,{ }^{1} \mathrm{H}$ and ${ }^{13} \mathrm{C}$ NMR spectra of compound 4 and 5, ATR-FTIR spectra of PBS and copolyesters 6, 7, 8 and 9.

Firdaus, M., and Meier, M. A. R. (2013). Renewable polyamides and polyurethanes derived from limonene. Green Chem. 15, 370-380. doi: 10.1039/C2GC36557J

Firdaus, M., Montero de Espinosa, L., and Meier, M. A. R. (2011). Terpene-based renewable monomers and polymers via thiol-ene additions. Macromolecules 44, 7253-7262. doi: 10.1021/ma201544e

Foote, C. S., and Wexler, S. (1964). Olefin oxidations with excited singlet molecular oxygen. J. Am. Chem. Soc. 86, 3879-3880. doi: 10.1021/ja01072a060

Geer, M. F., Walla, M. D., Solntsev, K. M., Strassert, C. A., and Shimizu, L. S. (2013). Self-assembled benzophenone bis-urea macrocycles facilitate selective oxidations by singlet oxygen. J. Org. Chem. 78, 5568-5578. doi: 10.1021/jo400685u

Gigli, M., Fabbri, M., Lotti, N., Gamberini, R., Rimini, B., and Munari, A. (2016). Poly(butylene succinate)-based polyesters for biomedical applications: a review. Eur. Polym. J. 75, 431-460. doi: 10.1016/j.eurpolymj.2016.01.016

Gigli, M., Lotti, N., Gazzano, M., Finelli, L., and Munari, A. (2012). Novel eco-friendly random copolyesters of poly(butylene succinate) containing ether-linkages. React. Funct. Polym. 72, 303-310. doi: 10.1016/j.reactfunctpolym.2012.02.013

Gualandi, C., Soccio, M., Saino, E., Focarete, M. L., Lotti, N., Munari, A., et al. (2012). Easily synthesized novel biodegradable copolyesters with adjustable properties for biomedical applications. Soft Matter 8, 5466-5476. doi: 10.1039/c2sm25308a

Guindani, C., Dozoretz, P., Araújo, P. H. H., Ferreira, S. R. S., and de Oliveira, D. (2019). N-acetylcysteine side-chain functionalization of poly(globalide-co$\varepsilon$-caprolactone) through thiol-ene reaction. Mater. Sci. Eng. C 94, 477-483. doi: 10.1016/j.msec.2018.09.060

Hauenstein, O., Reiter, M., Agarwal, S., Rieger, B., and Greiner, A. (2016). Biobased polycarbonate from limonene oxide and $\mathrm{CO} 2$ with high molecular weight, excellent thermal resistance, hardness and transparency. Green Chem. 18, 760-770. doi: 10.1039/C5GC01694K

Hoppe, R., Schulz-Ekloff, G., Wöhrle, D., Kirschhock, C., Fuess, H., Uytterhoeven, L., et al. (1995). Incorporation of methylene blue in NaY 
zeolite at crystallographically defined positions. Adv. Mater. 7, 61-64. doi: 10.1002/adma.19950070114

Hoyle, C. E., and Bowman, C. N. (2010). Thiol-ene click chemistry. Angew. Chem. Int. Ed. 49, 1540-1573. doi: 10.1002/anie.200903924

Ioannou, G. I., Montagnon, T., Kalaitzakis, D., Pergantis, S. A., and Vassilikogiannakis, G. (2017). A novel nebulizer-based continuous flow reactor: introducing the use of pneumatically generated aerosols for highly productive photooxidations. ChemPhotoChem 1, 173-177. doi: 10.1002/cptc.201600054

Jérôme, C., and Lecomte, P. (2008). Recent advances in the synthesis of aliphatic polyesters by ring-opening polymerization. Adv. Drug Deliv. Rev. 60, 1056-1076. doi: 10.1016/j.addr.2008.02.008

Kaanumalle, L. S., Shailaja, J., Robbins, R. J., and Ramamurthy, V. (2002). Cation controlled singlet oxygen mediated oxidation of olefins within zeolites. J. Photochem. Photobiol. A Chem. 153, 55-65. doi: 10.1016/S1010-6030(02)00297-6

Kobayashi, S., Lu, C., Hoye, T. R., and Hillmyer, M. A. (2009). Controlled polymerization of a cyclic diene prepared from the ring-closing metathesis of a naturally occurring monoterpene. J. Am. Chem. Soc. 131, 7960-7961. doi: $10.1021 /$ ja 9027567

Kohli, K., Prajapati, R., and Sharma, B. K. (2019). Bio-based chemicals from renewable biomass for integrated biorefineries. Energies 12:233. doi: $10.3390 /$ en 12020233

Kolb, N., and Meier, M. A. R. (2013). Grafting onto a renewable unsaturated polyester via thiol-ene chemistry and cross-metathesis. Eur. Polym. J. 49, 843-852. doi: 10.1016/j.eurpolymj.2012.09.017

Lowe, A. B. (2010). Thiol-ene "click" reactions and recent applications in polymer and materials synthesis. Polym. Chem. 1, 17-36. doi: 10.1039/B9PY00216B

Maurya, R. A., Park, C. P., and Kim, D.-P. (2011). Triple-channel microreactor for biphasic gas-liquid reactions: Photosensitized oxygenations. Beilstein J. Org. Chem. 7, 1158-1163. doi: 10.3762/bjoc.7.134

Monnerie, N., and Ortner, J. (2001). Economic evaluation of the industrial photosynthesis of rose oxide via lamp or solar operated photooxidation of citronellol. J. Solar Energy Eng. 123, 171-174. doi: 10.1115/1.1354996

Nardello, V., Caron, L., Aubry, J.-M., Bouttemy, S., Wirth, T., Saha-Möller Chantu, R., et al. (2004). Reactivity, chemoselectivity, and diastereoselectivity of the oxyfunctionalization of chiral allylic alcohols and derivatives in microemulsions: comparison of the chemical oxidation by the hydrogen peroxide/sodium molybdate system with the photooxygenation. J. Am. Chem. Soc. 126, 10692-10700. doi: 10.1021/ja048589f

Natarajan, A., Kaanumalle, L. S., Jockusch, S., Gibb, C. L. D., Gibb, B. C., Turro, N. J., et al. (2007). Controlling photoreactions with restricted spaces and weak intermolecular forces: exquisite selectivity during oxidation of olefins by singlet oxygen. J. Am. Chem. Soc. 129, 4132-4133. doi: 10.1021/ja070086x

Pace, A., and Clennan, E. L. (2002). A new experimental protocol for intrazeolite photooxidations. the first product-based estimate of an upper limit for the intrazeolite singlet oxygen lifetime. J. Am. Chem. Soc. 124, 11236-11237. doi: $10.1021 / \mathrm{ja} 027053 \mathrm{w}$

Park, C. Y., Kim, Y. J., Lim, H. J., Park, J. H., Kim, M. J., Seo, S. W., et al. (2015). Continuous flow photooxygenation of monoterpenes. RSC Adv. 5, 4233-4237. doi: $10.1039 / C 4 R A 12965 B$

Parrino, F., Fidalgo, A., Palmisano, L., Ilharco, L. M., Pagliaro, M., and Ciriminna, R. (2018). Polymers of limonene oxide and carbon dioxide: polycarbonates of the solar economy. ACS Omega 3, 4884-4890. doi: 10.1021/acsomega.8b00644

Parrish, B., and Emrick, T. (2006). "Strategies in aliphatic polyester synthesis for biomaterial and drug delivery applications," in Degradable Polymers and Materials, eds K. Khemani and C. Scholz (Washington, DC: American Chemical Society), 248-266. doi: 10.1021/bk-2006-0939.ch016

Pelegri-O'Day, E. M., Paluck, S. J., and Maynard, H. D. (2017). Substituted polyesters by thiol-ene modification: rapid diversification for therapeutic protein stabilization. J. Am. Chem. Soc. 139, 1145-1154. doi: $10.1021 /$ jacs.6b10776

Pounder, R. J., and Dove, A. P. (2010). Towards poly(ester) nanoparticles: recent advances in the synthesis of functional poly(ester)s by ring-opening polymerization. Polym. Chem. 1, 260-271. doi: 10.1039/b9py00327d

Ramamurthy, V., Sanderson, D. R., and Eaton, D. F. (1993). Control of dye assembly within zeolites: role of water. J. Am. Chem. Soc. 115, 10438-10439. doi: $10.1021 / \mathrm{ja} 00075 \mathrm{a} 101$
Rhodes, C. J. (2010). Properties and applications of Zeolites. Sci. Prog. 93, 223-284. doi: $10.3184 / 003685010 X 12800828155007$

Roth, S., Funk, I., Hofer, M., and Sieber, V. (2017). Chemoenzymatic synthesis of a novel borneol-based polyester. ChemSusChem 10, 3574-3580. doi: $10.1002 /$ cssc. 201701146

Schenck, G. O., Eggert, H., and Denk, W. (1953). Photochemische reaktionen III. Über die bildung von hydroperoxyden bei photosensibilisierten reaktionen von $\mathrm{O} 2$ mit geeigneten akzeptoren, insbesondere mit $\alpha$ - und ß-Pinen. Justus Liebigs Ann. Chem. 584, 177-198. doi: 10.1002/jlac.195358 40112

Shailaja, J., Sivaguru, J., Robbins, R. J., Ramamurthy, V., Sunoj, R. B., and Chandrasekhar, J. (2000). Singlet oxygen mediated oxidation of olefins within zeolites: selectivity and complexities. Tetrahedron 56, 6927-6943. doi: 10.1016/S0040-4020(00)00513-5

Soccio, M., Lotti, N., Gazzano, M., Govoni, M., Giordano, E., and Munari, A. (2012). Molecular architecture and solid-state properties of novel biocompatible PBS-based copolyesters containing sulphur atoms. React. Funct. Polym. 72, 856-867. doi: 10.1016/j.reactfunctpolym.2012. 08.002

Stamm, A., Tengdelius, M., Schmidt, B., Engström, J., Syrén, P. O., Fogelström, L., et al. (2019). Chemo-enzymatic pathways toward pinene-based renewable materials. Green Chem. 21, 2720-2731. doi: 10.1039/C9GC0 $0718 \mathrm{~K}$

Still, W. C., Kahn, M., and Mitra, A. (1978). Rapid chromatographic technique for preparative separations with moderate resolution. J. Org. Chem. 43, 2923-2925. doi: 10.1021/jo00408a041

Stratakis, M., and Froudakis, G. (2000). Site specificity in the photooxidation of some trisubstituted alkenes in Thionin-supported Zeolite Na-Y. On the role of the alkali metal cation. Org. Lett. 2, 1369-1372. doi: 10.1021/ol00 $0021 y$

Thomsett, M. R., Moore, J. C., Buchard, A., Stockman, R. A., and Howdle, S. M. (2019). New renewably-sourced polyesters from limonene-derived monomers. Green Chem. 21, 149-156. doi: 10.1039/C8GC02957A

Thomsett, M. R., Storr, T. E., Monaghan, O. R., Stockman, R. A., and Howdle, S. M. (2016). Progress in the synthesis of sustainable polymers from terpenes and terpenoids. Green Mater. 4, 115-134. doi: 10.1680/jgrma.16.00009

Trotta, J. T., Watts, A., Wong, A. R., LaPointe, A. M., Hillmyer, M. A., and Fors, B. P. (2019). Renewable thermosets and thermoplastics from itaconic acid. ACS Sustain. Chem. Eng. 7, 2691-2701. doi: 10.1021/acssuschemeng.8b 05766

Wahlen, J., De Vos, D. E., Jacobs, P. A., and Alsters, P. L. (2004). Solid materials as sources for synthetically useful singlet oxygen. Adv. Synth. Catal. 346, 152-164. doi: $10.1002 /$ adsc. 200303224

Wilbon, P. A., Chu, F., and Tang, C. (2013). Progress in renewable polymers from natural terpenes, terpenoids, and rosin. Macromol. Rapid Commun. 34, 8-37. doi: $10.1002 /$ marc. 201200513

Williams, C. K. (2007). Synthesis of functionalized biodegradable polyesters. Chem. Soc. Rev. 36, 1573-1580. doi: 10.1039/b614342n

Winnacker, M., and Rieger, B. (2015). Recent progress in sustainable polymers obtained from cyclic terpenes: synthesis, properties, and application potential. ChemSusChem 8, 2455-2471. doi: 10.1002/cssc.2015 00421

Zhang, D., Hillmyer, M. A., and Tolman, W. B. (2005). Catalytic polymerization of a cyclic ester derived from a "cool" natural precursor. Biomacromolecules 6 , 2091-2095. doi: 10.1021/bm050076t

Conflict of Interest: The authors declare that the research was conducted in the absence of any commercial or financial relationships that could be construed as a potential conflict of interest.

Copyright $\odot 2020$ Lanteri, Quattrosoldi, Soccio, Basso, Cavallo, Munari, Riva, Lotti and Moni. This is an open-access article distributed under the terms of the Creative Commons Attribution License (CC BY). The use, distribution or reproduction in other forums is permitted, provided the original author(s) and the copyright owner(s) are credited and that the original publication in this journal is cited, in accordance with accepted academic practice. No use, distribution or reproduction is permitted which does not comply with these terms. 